\title{
Therapeutic disruption of Plasmodium vivax infected red cell deformability
}

\author{
Rou Zhang ${ }^{1}$, Wenn-Chyau Lee ${ }^{2}$, Benoit Malleret ${ }^{1,3}$, Rossarin Suwanarusk ${ }^{3}$, Ming Dao ${ }^{6}$, Cindy $\mathrm{Chu}^{4,5}$, \\ Chwee Teck Lim7, Laurent Renia ${ }^{3}$, Francois Nosten ${ }^{4,5}$, Bruce Russell ${ }^{\text {* }}$ \\ From Challanges in malaria research: Core science and innovation \\ Oxford, UK. 22-24 September 2014
}

\section{Background}

Chloroquine (CQ) and artesunate (AS) are widely used as blood schizontocides in P. vivax treatment. Recent clinical observations show late stage parasites are cleared more rapidly than expected post treatment. As the high deformability of $P$. vivax facilitates its escaping from the splenic clearance, we hypothesize that CQ and AS directly affect the $P$. vivax infected red blood cells (iRBCs) rigidity. As a consequence, parasites are rapidly cleared from the blood circulation.

\section{Materials and methods}

$P$. vivax isolates from Thailand were pulse incubated with AS, CQ and a spiroindolone (NITD609). Morphological changes and rosetting frequency were assessed by sub vital staining. The micropipette aspiration technique was the used to quantify the cell membrane shear modulus. Microfluidics were used to study the in vitro iRBCs behaviour after drug treatment.

\section{Results}

While CQ and AS did not directly affect iRBC shear modulus, it significantly enhanced rosetting frequency and consequently the rigidity of rosetted iRBCs (the attachment of a single red cell results in a significant increase in shear modulus of the iRBC). NITD609 directly affected the iRBC rigidity. A microfluidic model of the spleen shows that $P$. vivax iRBCs with a higher rigidity are removed from flow. This study also show that normocytes that rosette with $P$. vivax iRBCs; form strong attachments $(\sim 500 \mathrm{pN})$ that withstand a range of physiological shear stresses.

'Department of Microbiology, Yong Loo Lin School of Medicine, National University of Singapore, Singapore

Full list of author information is available at the end of the article

\section{Conclusions}

In addition to providing new and important baseline biomechanical data on $P$. vivax rosettes; this ex vivo study also provides a possible explanation for the clinically observed disappearance of $P$. vivax parasites soon after treatment.

\section{Authors' details}

'Department of Microbiology, Yong Loo Lin School of Medicine, National University of Singapore, Singapore. ${ }^{2}$ Department of Parasitology, Faculty of Medicine, University of Malaya, Kuala Lumpur, Malaysia. ${ }^{3}$ Singapore Immunology Network (SIgN), A*STAR, Biopolis, Singapore. ${ }^{4}$ Centre for Tropical Medicine, Nuffield Department of Medicine, University of Oxford, Oxford, UK. ${ }^{5}$ Shoklo Malaria Research Unit, Mahidol-Oxford Tropical Medicine Research Unit, Faculty of Tropical Medicine, Mahidol University, Mae Sod, Thailand. ${ }^{6}$ Department of Materials Science and Engineering, Massachusetts Institute of Technology, Cambridge, MA, USA. ${ }^{7}$ Department of Biomedical Engineering Faculty of Engineering, National University of Singapore, Singapore.

Published: 22 September 2014

doi:10.1186/1475-2875-13-S1-025

Cite this article as: Zhang et al: Therapeutic disruption of Plasmodium vivax infected red cell deformability. Malaria Journal 2014 13(Suppl 1):O25.

Submit your next manuscript to BioMed Central and take full advantage of:

- Convenient online submission

- Thorough peer review

- No space constraints or color figure charges

- Immediate publication on acceptance

- Inclusion in PubMed, CAS, Scopus and Google Scholar

- Research which is freely available for redistribution

Submit your manuscript at www.biomedcentral.com/submit
() Biomed Central 